\title{
Descent in Symmetry during Solid State Transitions and Other Anomalies in Mixed Valence Compounds
}

$$
A_{X} M_{X}^{I I} M_{1-X}^{I I I} F_{3}(A=K, R b, C s ; M=V, C r ; x=0.0-1.0)
$$

\author{
William 0. J. Boo', Daniell L. Mattern'1, Robert M. Metzger ${ }^{2}$ \\ ${ }^{1}$ Department of Chemistry and Biochemistry, University of Mississippi, University, MS, USA; ${ }^{2}$ Department of \\ Chemistry and Biochemistry, University of Alabama, Tuscaloosa, AL, USA
}

Correspondence to: Daniell L. Mattern, mattern@olemiss.edu

Keywords: Descent in Symmetry, Ionic Ordering, Magnetic Ordering, Magnetic Susceptibility, Reconstructive Transitions Received: May 30, 2019 Accepted: June 27, $2019 \quad$ Published: June 30, 2019

Copyright $\odot 2019$ by author(s) and Scientific Research Publishing Inc.

This work is licensed under the Creative Commons Attribution International License (CC BY 4.0).

http://creativecommons.org/licenses/by/4.0/

(c) (i) Open Access

\section{ABSTRACT}

The scope of solid-state transitions, from melting temperatures down to $4.2 \mathrm{~K}$, is described for six systems: $\mathrm{K}_{\mathrm{x}} \mathrm{VF}_{3}, \mathrm{Rb}_{\mathrm{x}} \mathrm{VF}_{3}, \mathrm{Cs}_{\mathrm{x}} \mathrm{VF}_{3}, \mathrm{~K}_{\mathrm{x}} \mathrm{CrF}_{3}, \mathrm{Rb}_{\mathrm{x}} \mathrm{CrF}_{3}$, and $\mathrm{Cs}_{\mathrm{x}} \mathrm{CrF}_{3}$ (for $\mathrm{x}=0.0$ to 1.0). Connections are drawn between the compounds' compositions and structures with the various transitions and ordering events. Upon solidification from the melt and gradual cooling to room temperature, a sequential descent of symmetry appears to occur, from high-symmetry perovskite phases, through possible reconstructive transitions, to phases designated $\alpha, \beta$, and $\delta$, within which ionic ordering finally sets in, forming many new lower-symmetry structures. Many stable new structures are seen at room temperature. Finally, at cryogenic temperatures, magnetic ordering sets in. Other anomalies for these systems are also described. The analysis underscores the overall correspondence of structure, composition, and magnetic properties in these compounds. This lowering of symmetry mirrors what has been chronicled for oxygen-bearing perovskites that have yielded so many high-temperature ceramic superconductors.

\section{HISTORICAL NOTE}

William O. J. Boo was a professor of chemistry at the University of Mississippi from 1967 to 1992 . He died on 7 September, 2011, leaving unfinished this manuscript which reviews his two decades of research in the lower-valence fluorides of vanadium and chromium. The manuscript has been completed by two of his former colleagues, Daniell L. Mattern and Robert M. Metzger. Professor Boo also had a long-standing interest in symmetry, constructing hook-and-loop-edged polygons to teach geometry symmetry principles to elementary-school students, including tilings, solid shapes, and packings as shown in Figure 4 below. 


\section{INTRODUCTION}

This study reviews the structures, transitions, ionic and magnetic ordering phenomena, and other anomalous behaviors of six lower-valence fluorides of vanadium and chromium, $\mathrm{A}_{\mathrm{x}} \mathrm{MF}_{3}$, designated as $\mathrm{A}_{\mathrm{x}} \mathrm{M}_{X}^{\mathrm{II}} \mathrm{M}_{1-\mathrm{x}}^{\mathrm{III}} \mathrm{F}_{3} \quad\left(\mathrm{~A}_{\mathrm{x}} \mathrm{MF}_{3}\right)$, where $\mathrm{A}=\mathrm{K}, \mathrm{Rb}$, or Cs; $\mathrm{M}=\mathrm{V}$ or $\mathrm{Cr}$; and $\mathrm{x}=0.0-1.0$. Descent in symmetry in oxygen-containing perovskites was reviewed by Goodenough [1] decades before the ceramic superconductors $\mathrm{La}_{2-\mathrm{x}} \mathrm{CuO}_{4}$ [2] and $\mathrm{YBaCuO}_{7-\mathrm{x}}$ [3] were discovered within that family [4]. A recent article describes how charge ordering in lanthanide cuprates is related to unusual collective behavior, such as antiferromagnetism and superconductivity [5].

The alkali metal ions $\mathrm{K}^{+}, \mathrm{Rb}^{+}$, and $\mathrm{Cs}^{+}$(the $\mathrm{A}^{+}$ions) demonstrate the effects of their sizes and concentrations on crystal structures. $\mathrm{V}^{2+}, \mathrm{V}^{3+}, \mathrm{Cr}^{2+}$, and $\mathrm{Cr}^{3+}$ are first-row transition-metal ions with simple $3 \mathrm{~d}$ electronic configurations. The $\mathrm{F}^{-}$ion is small and has small polarizability. It is a weak field ligand (compared to the $\mathrm{O}^{2-}$ ion), and the $\mathrm{V}$ and $\mathrm{Cr}$ ions, which are octahedrally coordinated by $\mathrm{F}^{-}$ions, have high-spin electronic configurations (Figure 1). M-F bonds have mostly ionic character, but their covalency is strong enough to form 3-D network structures.

On the other hand, due to the weak bonding in the network, the structures easily adapt to the sizes and concentrations of the $\mathrm{A}^{+}$ions. Hence, the corner-sharing $\mathrm{MF}_{6}$ octahedra are flexible enough to give rise to a variety of closed-network structures [6]. The weak covalency of the M-F bonds also facilitates super-exchange interactions between nearest-neighboring magnetic centers.

Figure 2 outlines the temperature regions in which the various transitions appear to be occurring. At first, perovskite-like solid phases apparently form from the melt [7]. Upon cooling, new structures are formed, designated $\alpha, \beta$, and $\delta$ [8-10]; when these are cooled further, ionic ordering sets in [7, 11-15]. Such transitions are characteristic of mixed-valence compounds $[1,16]$. Three ordered structures are possible in the $\alpha$-phases, three in the $\beta$-phases, and two in the $\delta$-phases [7]. At very low temperatures (below $50 \mathrm{~K}$ ), magnetic ordering sets in [11-14]. These transformations correspond to a descent in symmetry during the phase changes, from averaged and mixed-valent arrangements to more ordered ones.

Some anomalies are associated with specific phases, such as the metamagnetic transition that occurs with $\mathrm{K}_{0.49} \mathrm{VF}_{3}$ [11]. In addition, behaviors associated with specific ions occur, such as the orbital quenching of $\mathrm{V}^{3+}[11]$.

In the remainder of this paper, we will describe the melting temperatures of the compounds, and then detail descriptions of the reconstructive transitions and the ionic and magnetic ordering that sets in as the temperature is lowered.

\section{MELTING TEMPERATURES}

The melting temperatures of the $\mathrm{A}_{\mathrm{x}} \mathrm{MF}_{3}$ compounds [7] are shown in Figure 3. Remarkably, the $\mathrm{A}_{\mathrm{x}} \mathrm{CrF}_{3}$ compounds all melt $200^{\circ}$ lower than their $\mathrm{A}_{\mathrm{x}} \mathrm{VF}_{3}$ analogs. The other striking feature of Figure 3 is that the melting temperature vs. $\mathrm{x}$ plots of the $\mathrm{A}_{\mathrm{x}} \mathrm{MF}_{3}$ systems are all linear. These plots include the binary parent compounds $\mathrm{VF}_{3}$ and $\mathrm{CrF}_{3}$, which have cubic perovskite-like structures at high temperatures [7, 17]. This suggests that the $\mathrm{A}_{\mathrm{x}} \mathrm{MF}_{3}$ compounds also initially solidify to cubic-perovskite-like structures.



Figure 1. Electronic configurations of $\mathrm{V}^{2+}, \mathrm{V}^{3+}, \mathrm{Cr}^{2+}$, and $\mathrm{Cr}^{3+}$ in a weak octahedral field. 




Figure 2. Temperature regimes for various likely ordering phenomena of the $\mathrm{A}_{\mathbf{x}} \mathrm{MF}_{3}$ compounds. The wavy lines and the interpretation of the ordering processes above room temperature have partial support from DTA transitions [7].

\section{RECONSTRUCTIVE TRANSITIONS}

The high-temperature DTA data [7] suggest (Figure 2) a succession of reconstructive transitions between $900^{\circ} \mathrm{C}$ and $650^{\circ} \mathrm{C}$, that break up the perovskite structure and form new lattices, designated $\alpha, \beta$, and $\delta$ [1]. Such $\alpha, \beta$, and $\delta$ phases have only been reported for first-row transition-metal fluorides. (Note that $\mathrm{MF}_{3}$ and $\mathrm{AMF}_{3}$ [18] are not mixed-valence compounds, and do not undergo reconstructive transitions. The variety of crystal structures of metal fluorides has been recently reviewed. [19]) Since a perovskite phase does form upon solidification [7, 17], we surmise that single crystals of the lower-symmetry $\alpha, \beta$, and $\delta$ phases will grow at temperatures considerably below the solidification temperatures.

The structural analogs of the $\mathrm{A}_{\mathrm{x}} \mathrm{MF}_{3}$ compounds [7] include: cubic perovskite $\left(\mathrm{SrTiO}_{3}\right)$ and rhenium oxide $\left(\mathrm{ReO}_{3}\right)(\mathrm{x}=1.0, \gamma$ phase, each belonging to space group $\mathrm{Pm} \overline{3} \mathrm{~m}=\# 221)$ [20]; hexagonal tungsten bronze (HTB) $\left(\mathrm{x}=0.167\right.$ to $\mathrm{x}=0.31, \alpha$ phase, space group $\left.\mathrm{P}_{3} / \mathrm{mcm}=\# 185\right)$ [21]; tetragonal tungsten bronze (TTB) $(\mathrm{x}=0.45$ to $\mathrm{x}=0.60, \beta$ phase, space group $\mathrm{P} 4 / \mathrm{mbm}=\# 127)$ [22] or hexagonal $\mathrm{BaTa}_{2} \mathrm{O}_{6}(\mathrm{x}=$ 0.43 to $\mathrm{x}=0.52, \beta$ phase, space group $\mathrm{P} 6 / \mathrm{mmm}=\# 191$ [21], which is a structure similar to TTB [23]; and finally modified pyrochlore (MP) $(\mathrm{x}=0.45$ to $\mathrm{x}=0.58, \delta$ phase, space group $\mathrm{Fd} \overline{3} \mathrm{~m}=\# 227)$ [24]. The value of $\mathrm{x}$ alone cannot discriminate between the $\beta$ phase and the $\delta$ phase [7].

The structures of the $\mathrm{A}_{\mathrm{x}} \mathrm{MF}_{3}$ compounds have topologies which can be described using packings of simple geometrical shapes: cubic perovskite with a packing of cubes; HTB with a packing of triangular and hexagonal prisms in the ratio 2:1 (Figure 4(a)); TTB with triangular, square, and distorted pentagonal prisms 2:1:2 (Figure 4(b)); and MP with a packing of tetrahedra and truncated tetrahedra 1:1 (Figure 4(c)). Each of the packings is used in the same way. The transition metal ions are located on all vertices, the $\mathrm{F}^{-}$ions approximately in the centers of all edges, and the $\mathrm{A}^{+}$ions in the centers of some or all of the 3-dimensional holes. 

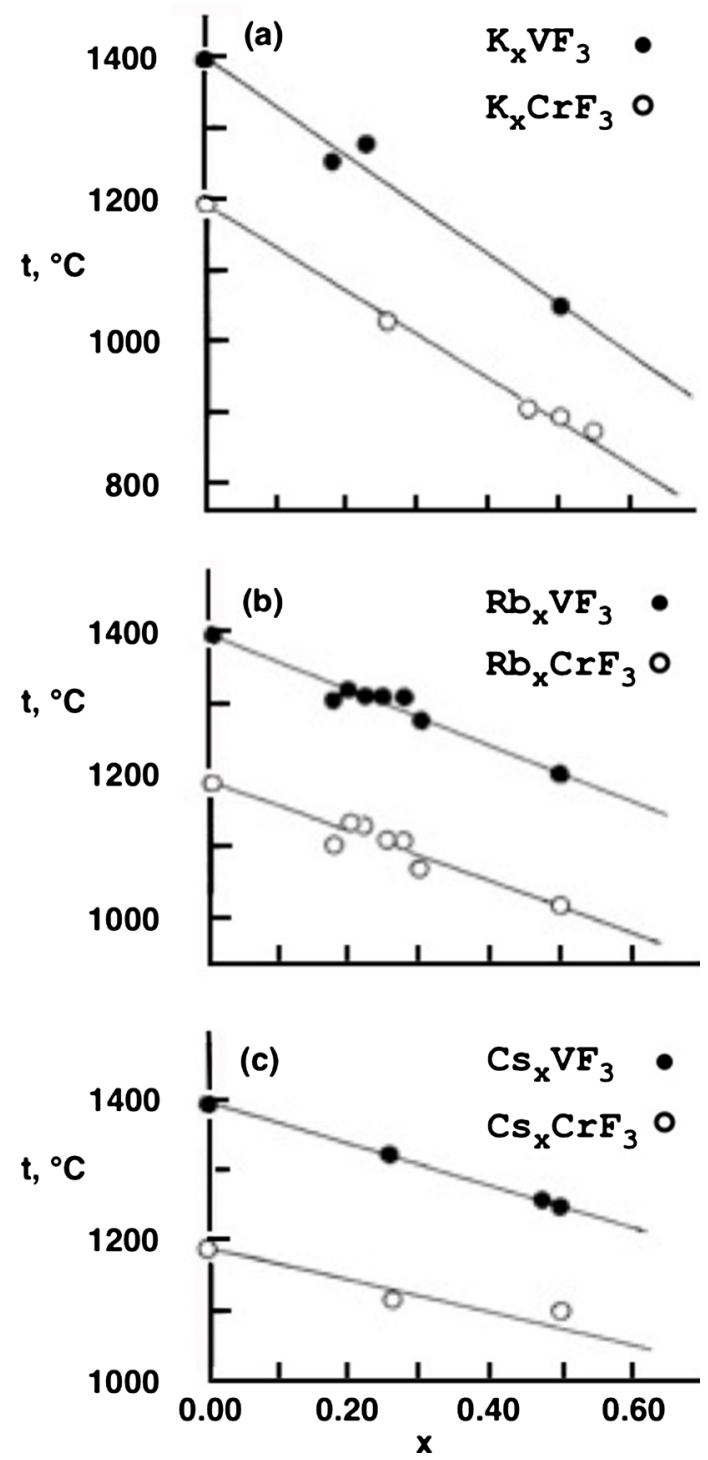

Figure 3. Melting temperatures $\left({ }^{\circ} \mathrm{C}\right)$ of the $\mathrm{A}_{\mathrm{x}} \mathrm{MF}_{3}$ compounds. Data from ref [7].

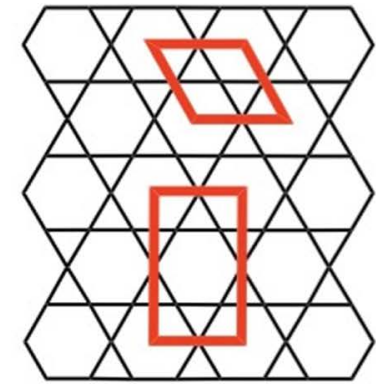

(a)

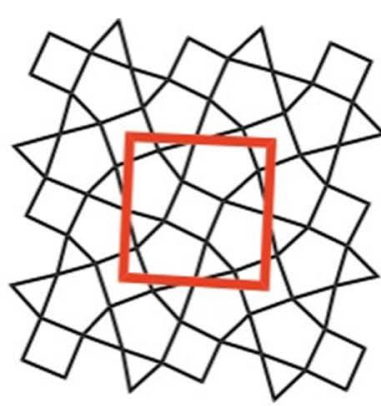

(b)

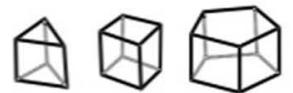

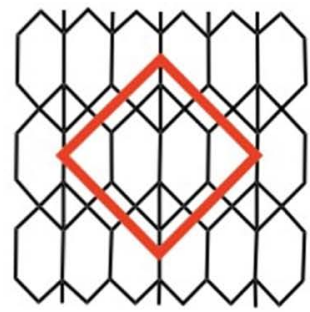

(c)

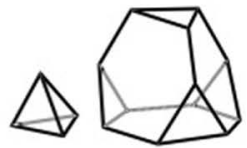

Figure 4. Geometrical configurations of (a) the HTB structure, showing the hexagonal unit cell (upper) and the ortho-hexagonal unit cell (lower); (b) the TTB structure, showing the tetragonal unit cell; and (c) the MP structure, showing the cubic unit cell. 
A packing of cubes is a regular packing; a (1:1) - (tetrahedron:truncated-tetrahedron) packing is quasi-regular, while a (2:1) —(triangular-prism:hexagonal-prism) packing is semi-regular. The significance is that in each of these geometrical packings, the vertices (where transition metal ions reside) are congruent. The packing of triangular prisms, square prisms, and distorted pentagonal prisms has two sets of vertices, but all of the edges are of equal length. These packings each reveal that the $\mathrm{MF}_{6}(\mathrm{M}=\mathrm{V}, \mathrm{Cr})$ octahedra share corners with six other octahedra, and all M-F-M bond angles are approximately $180^{\circ}$.

$\mathrm{VF}_{3}$ and $\mathrm{CrF}_{3}$ have lattices that collapse from cubic to rhombohedral near $500^{\circ} \mathrm{C}[7,25]$. These are not reconstructive transitions, since their network structures are displaced, but not broken.

\section{IONIC ORDERING}

When they are cooled further, the $\mathrm{A}_{\mathrm{x}} \mathrm{MF}_{3}$ compounds likely experience a variety of ionic ordering phenomena [7]. The space-group symmetries of the ordered structures are sub-groups of the $\alpha, \beta$, or $\delta$ parent structures [26].

In the $\mathrm{A}_{\mathrm{x}} \mathrm{CrF}_{3}$ compounds, ionic ordering includes $\left(\mathrm{Cr}^{2+} / \mathrm{Cr}^{3+}\right)$ electronic ordering, ordering of partially-filled $\mathrm{A}^{+}$sites, and $\left(\mathrm{Cr}^{2+}\right)$ Jahn-Teller ordering. These ordering phenomena probably occur cooperatively between $500^{\circ} \mathrm{C}$ and $300^{\circ} \mathrm{C}$. The $\mathrm{A}_{\mathrm{x}} \mathrm{VF}_{3}$ compounds undergo $\left(\mathrm{V}^{2+} / \mathrm{V}^{3+}\right)$ charge ordering, ordering of partially filled $\mathrm{A}^{+}$sites, and $\left(\mathrm{V}^{3+}\right)$ Jahn-Teller ordering between $300^{\circ} \mathrm{C}$ and $100^{\circ} \mathrm{C}$ [7].

Three modulated structures are possible in the $\alpha$ phases: these correspond to $1 / 2$-filled $\mathrm{A}^{+}$sites $(\mathrm{x}=$ 0.167, space group Pnnm \# 58); $2 / 3$-filled $\mathrm{A}^{+}$sites $\left(\mathrm{x}=0.222\right.$, space group $\mathrm{Cmcm} \# 63$ ); and 3/4-filled $\mathrm{A}^{+}$ sites $(\mathrm{x}=0.250$, space group Pmma \#51) $[12,13]$. The $\alpha(0.222)$ and $\alpha(0.250)$ structures only form if samples are cooled slowly; $\alpha(0.167)$, however, is more tenacious, and forms no matter how rapidly the samples are cooled. Table 1 lists which modulated structures form in each of the six systems. The Jahn-Teller ions

Table 1. Modulated structures and distortion ratios $\left[\mathrm{a} /\left(3^{1 / 2} \mathrm{~b}\right)\right]$ in the $\boldsymbol{a}$-phases (hettotype of HTB). At least in the Cr salts, note the "Goldilocks" effect, where the $\mathrm{K}^{+}$ion is too small $\left\{a /\left(3^{1 / 2} \mathrm{~b}\right)>1\right\}$, and $\mathrm{Cs}^{+}$is too large $\left\{a /\left(3^{1 / 2} b\right)<1\right\}$, but $\mathbf{R b}^{+}$is just right $\left\{a /\left(3^{1 / 2} b\right) \approx 1\right\}$, to form all three modulated structures $\alpha(0.167), \alpha(0.222)$, and $\alpha(0.250)$. Data from ref. [7].

\begin{tabular}{ccccc}
\hline $\mathrm{x}=$ & 0.19 & 0.22 & 0.25 & 0.28 \\
$\mathrm{~K}_{\mathbf{x}} \mathrm{VF}_{3}$ & $\alpha(0.167)$ & $\alpha(0.222)$ & - & - \\
& 1.007 & 1.006 & 1.006 & 0.991 \\
$\mathrm{Rb}_{\mathbf{x}} \mathrm{VF}_{3}$ & $\alpha(0.167)$ & $\alpha(0.222)$ & $A(0.250)$ & - \\
& 1.005 & 1.004 & 0.991 & 0.992 \\
$\mathrm{Cs}_{\mathbf{x}} \mathrm{VF}_{3}$ & - & $\alpha(0.222)$ & $\alpha(0.250)$ & - \\
& 0.997 & 0.997 & 0.998 & 0.998 \\
$\mathrm{~K}_{\mathbf{x}} \mathrm{CrF}_{3}$ & - & - & - & - \\
& 1.027 & 1.031 & 1.029 & 1.031 \\
$\mathrm{Rb}_{\mathbf{x}} \mathrm{CrF}_{3}$ & $\alpha(0.167)$ & $\alpha(0.222)$ & $\alpha(0.250)$ & - \\
& 0.991 & 0.978 & 0.980 & 0.994 \\
$\mathrm{Cs}_{\mathbf{x}} \mathrm{CrF}_{3}$ & - & $\alpha(0.222)$ & $\alpha(0.250)$ & - \\
& 0.987 & 0.986 & 0.990 & 0.987 \\
\hline
\end{tabular}


$\mathrm{V}^{3+}$ and $\mathrm{Cr}^{2+}$ distort their $\alpha$ phase compounds from hexagonal to orthorhombic, even when no modulated structures are formed. The distortion of the hexagonal unit cell is expressed as $|a| /\left(3^{1 / 2}|b|\right)$; this ratio can be greater than, or less than, 1.000 .

In the $\beta$-phases, three ionically-ordered structures are possible, in addition to the hexagonal $\mathrm{BaTa}_{2} \mathrm{O}_{6}$ structure. The three ordered structures are: a distorted $\mathrm{BaTa}_{2} \mathrm{O}_{6}$ structure (space group Cmmm \#47), an ordered TTB structure (space group $\mathrm{P} 4{ }_{2} \mathrm{bc} \# 106$ ), and a distorted TTB structure (space group Pba2 \#32) [7, 9]. In the $\beta$-phase of $\mathrm{K}_{\mathrm{x}} \mathrm{VF}_{3}$ the ionically-ordered TTB structure forms over the range $\mathrm{x}=0.45-0.56$. Only a trace amount of the ordered $\mathrm{BaTa}_{2} \mathrm{O}_{6}$ structure forms near $\mathrm{x}=0.40$ [27]. In the $\beta$ phase of $\mathrm{K}_{\mathrm{x}} \mathrm{CrF}_{3}(\mathrm{x}=$ 0.43 - 0.59), the hexagonal $\mathrm{BaTa}_{2} \mathrm{O}_{6}$ structure forms if the sample is cooled slowly [28]. If the sample is cooled rapidly, the distorted TTB structure forms, and if the sample is cooled at an intermediate rate, the hexagonal $\mathrm{BaTa}_{2} \mathrm{O}_{6}$ structure forms at low $\mathrm{x}$, the distorted TTB structure forms at high $\mathrm{x}$, and the ordered $\mathrm{BaTa}_{2} \mathrm{O}_{6}$ structure forms in the intermediate region of $\mathrm{x}$ [14].

In the $\delta$-phases, the fcc MP structure plus two ionically-ordered MP structures are possible. In the ordered structures, $\mathrm{M}^{2+}$ ions form linear chains along the $<110>$ direction and $\mathrm{M}^{3+}$ ions form linear chains along the $<110\rangle$ direction. One of the ordered structures is body-centered orthorhombic MP (space group Imma \#74). The second ordered structure is distorted to primitive orthorhombic MP (space group Pmna \#53). The $\delta$-phase of $\mathrm{Rb}_{\mathrm{x}} \mathrm{VF}_{3}(\mathrm{x}=0.45-0.52)$ has the fcc structure at $\mathrm{x}=0.45$ and the primitive orthorhombic structure for $\mathrm{x}$ above 0.45 . In the $\delta$-phase of $\mathrm{Cs}_{\mathrm{x}} \mathrm{VF}_{3}(\mathrm{x}=0.45-0.52)$, the fcc structure exists below $\mathrm{x}=0.50$ but the body-centered orthorhombic structure occurs above $\mathrm{x}=0.50$. The phases of $\mathrm{Rb}_{\mathrm{x}} \mathrm{CrF}_{3}(\mathrm{x}=0.45$ 0.56) and $\mathrm{Cs}_{\mathrm{x}} \mathrm{CrF}_{3}(\mathrm{x}=0.46-0.54)$ have primitive orthorhombic structures over their entire range of $\mathrm{x}$ [7].

\section{ORBITAL QUENCHING OF THE V³+ ION}

The Curie-Weiss law may be stated as:

$$
\chi_{M}=C_{M} /(T-\theta)
$$

where $\chi_{M}$ is the molar magnetic susceptibility, $C_{M}$ is the Curie constant, $\theta$ is the Weiss constant, and $T$ is the absolute temperature. A plot of $1 / \chi_{M}$ vs $T$ usually displays a linear region for paramagnetic compounds, with the slope of that region equal to $C_{M}^{-1}$. For $\mathrm{VF}_{3}$ however, the plot displays 2 linear regions [29], because the orbital magnetic moment of $\mathrm{V}^{3+}$ is only partially quenched at high temperatures, but is totally quenched below $122 \mathrm{~K}$. This phenomenon occurs in some (but not all) of the $\mathrm{A}_{\mathrm{x}} \mathrm{VF}_{3}$ compounds as well [15]. A plot of $1 / \chi_{M}$ vs $T$ for $\mathrm{K}_{0.250} \mathrm{VF}_{3}$, shown in Figure 5, is an example of a compound in which the orbital

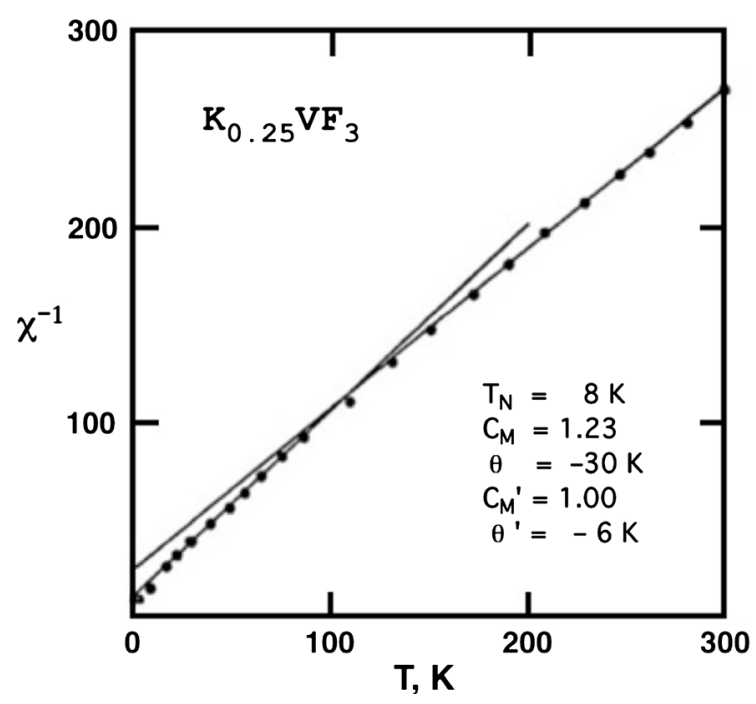

Figure 5. $\chi_{M}^{-1}$ versus $T$ of $\mathrm{K}_{0.25} \mathrm{VF}_{3}$. Data from ref [15]. 
moment of $\mathrm{V}^{3+}$ becomes totally quenched near $100 \mathrm{~K}$.

For the $\mathrm{A}_{\mathrm{x}} \mathrm{VF}_{3}$ compounds, $C_{M}=\mathrm{x} C_{M}[+2]+(1-\mathrm{x}) C_{M}[+3]$, where $C_{M}[+2]$ and $C_{M}[+3]$ are the $\mathrm{V}^{2+}$ and $\mathrm{V}^{3+}$ components of $C_{M}$, respectively. When the $\mathrm{V}^{3+}$ ion is totally quenched, the value of $C_{M}$ falls on a straight line that connects $C_{M}\left(\mathrm{VF}_{3}\right)$ at x $=0.0$ with $C_{M}\left(\mathrm{AVF}_{3}\right)$ at x $=1.0$. Figure 6 shows plots of $C_{M} \mathrm{vs} \mathrm{x}$ for $\mathrm{K}_{\mathrm{x}} \mathrm{VF}_{3}, \mathrm{Rb}_{\mathrm{x}} \mathrm{VF}_{3}$, and $\mathrm{Cs}_{\mathrm{x}} \mathrm{VF}_{3}$ in which $\mathrm{C}_{M}$ values were obtained from the temperature region 50 to $150 \mathrm{~K}$. Figure 6 clearly shows that the $\mathrm{V}^{3+}$ orbitals in the $\alpha$ phases are totally quenched, those in the $\beta$ phases remain partially quenched, and those in the $\delta$ phases become totally quenched if they have the fcc structure, but remain only partially quenched if they have the body centered or primitive orthorhombic structures.

\section{EXCITATION OF A SECOND ORBITAL STATE OF Cr²+}

In $\mathrm{CrF}_{2}$ a second orbital state approximately $116 \mathrm{~cm}^{-1}$ above the ground orbital state was observed [30]. This excitation appears as a shoulder in a $C(\mathrm{mag})$ vs $\mathrm{T}$ plot near $80 \mathrm{~K}$, which leads to an additional Rln2 contribution to $S$ (mag), making the total $S$ (mag) Rln10 rather than Rln5. The magnetic susceptibility of $\mathrm{CrF}_{2}$ emulates those of the $\beta$ phase $\mathrm{K}_{\mathrm{x}} \mathrm{CrF}_{3}$ compounds, see Figure 7 [14]. Evidence of $\mathrm{Cr}^{2+}$ in these compounds behaving the same as in $\mathrm{CrF}_{2}$, however, is inconclusive.

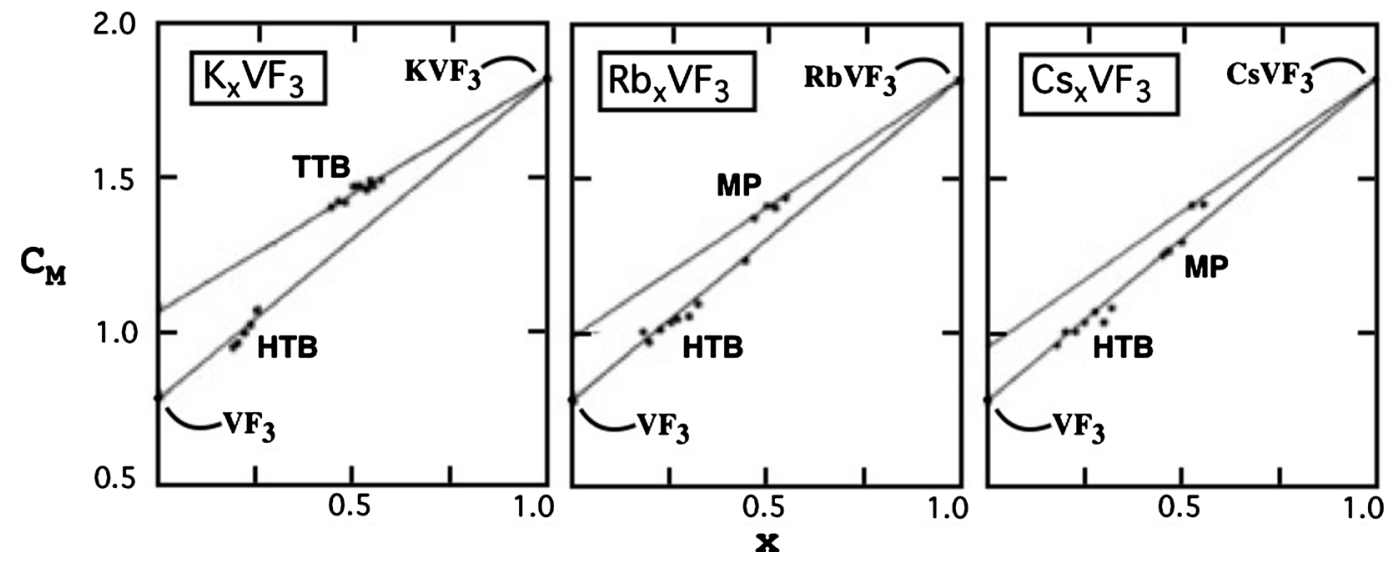

Figure 6. $C_{M}$ below $150 \mathrm{~K}$ versus $x$ of the $A_{x} V_{3}$ compounds. Data from refs $[13,14]$.

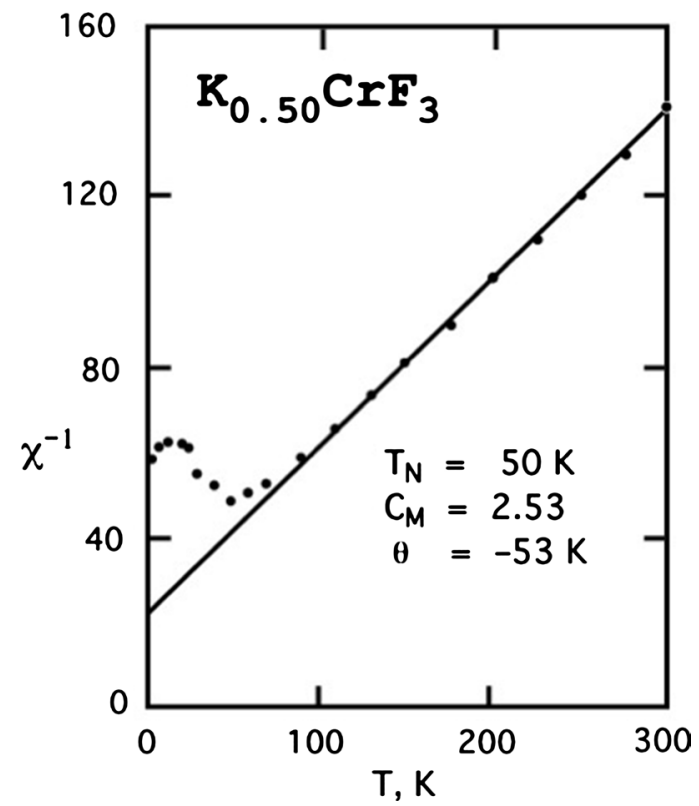

Figure 7. $\chi_{M}^{-1}$ versus $\mathrm{T}$ for $\mathrm{K}_{0.50} \mathrm{CrF}_{3}$. Data from ref [14]. 


\section{MAGNETIC ORDERING}

Magnetic interactions in the $\mathrm{A}_{\mathrm{x}} \mathrm{MF}_{3}$ compounds are primarily antiferromagnetic, and weak ferromagnetic interactions are often difficult to detect in these complex structures. There are four observable magnetic parameters: $C_{M}$ (the Curie constant), $T_{C}$ (the Curie temperature), $\theta$ (the Weiss constant), and $\sigma_{\mathrm{o}}$ (the spontaneous magnetic moment extrapolated to $0 \mathrm{~K}$ ).

The $C_{M}$ values of the $\mathrm{A}_{\mathrm{x}} \mathrm{VF}_{3}$ compounds below $150 \mathrm{~K}$ are shown in Figure 6. Observed $C_{M}$ values of the $\mathrm{A}_{\mathrm{x}} \mathrm{CrF}_{3}$ compounds are in good agreement with calculated spin-only values, except for the $\alpha(0.167)$ structure of $\mathrm{Rb}_{\mathrm{x}} \mathrm{CrF}_{3}$ [13] and the $\beta$-phase of $\mathrm{K}_{\mathrm{x}} \mathrm{CrF}_{3}$ [14] (both at temperatures below $150 \mathrm{~K}$ ). Possible explanations were given in the previous section for $\mathrm{K}_{\mathrm{x}} \mathrm{CrF}_{3}$ and have been discussed before for $\alpha(0.167)$ of $\mathrm{Rb}_{\mathrm{x}} \mathrm{CrF}_{3}[13]$.

The $T_{C}$ value, the temperature at which long range magnetic ordering sets in, is usually seen as a maximum in a $\chi_{M}$ vs $T$ plot. Most of the $\mathrm{A}_{\mathrm{x}} \mathrm{MF}_{3}$ compounds, however, display small spontaneous magnetic moments $(\sigma)$ that mask these maxima. In these cases, $T_{C}$ is determined by the onset of $\sigma$. Figure 8 shows
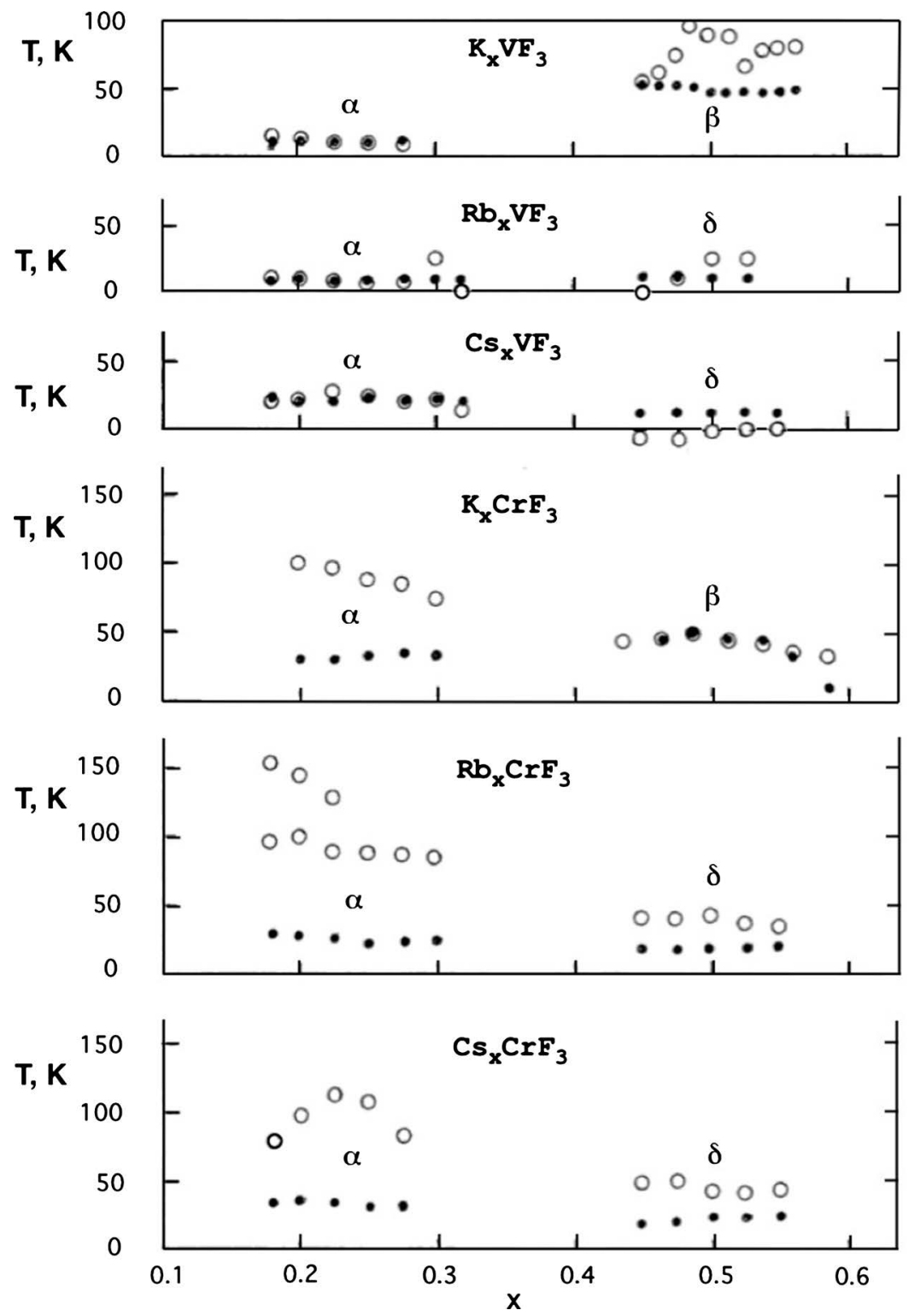

Figure 8. $T_{N}(\bullet)$ and $-\theta(O)$ for the six $\mathrm{A}_{\mathrm{x}} \mathrm{MF}_{3}$ systems. Data from ref [13-15]. 
$T_{C}$ and $-\theta$ values of the six systems. In general, the $T_{C}$ values of the $\mathrm{A}_{\mathrm{x}} \mathrm{VF}_{3}$ compounds are lower than their $\mathrm{A}_{\mathrm{x}} \mathrm{CrF}_{3}$ analogs. The substitution of different $\mathrm{A}^{+}$ions appear to have little effect on the magnetic properties. The three structures of the $\beta$ phase of $\mathrm{K}_{\mathrm{x}} \mathrm{CrF}_{3}$ have unique $T_{C}$ values: the hexagonal $\mathrm{BaTa}_{2} \mathrm{O}_{6}$ structure shows no evidence of $T_{\dot{O}}$ for the ordered $\mathrm{BaTa}_{2} \mathrm{O}_{6}$ structure, $T_{C}=50 \mathrm{~K}$; and for the distorted TTB structure, $T_{C}=10$ $\mathrm{K}$. The $T_{C}$ values of the other phases appear to be essentially constant over their entire range of $\mathrm{x}$.

$\theta$ values provide a measure of the strength and sign of magnetic interactions at temperatures above $T_{N}$. Except for the $\beta$ phases of $\mathrm{K}_{\mathrm{x}} \mathrm{CrF}_{3},|\theta|$ values of the $\mathrm{Cr}$ compounds are greater than their $\mathrm{V}$ analogs. The $|\theta|$ values of the $\alpha$-phases of $\mathrm{Cr}$ are remarkably large compared with the $\beta$ and $\delta$-phases of $\mathrm{Cr}$. $\mathrm{Rb}_{0.167} \mathrm{CrF}_{3}$ displays two $\theta$ values, $\theta$ from the high temperature region and $\theta^{\prime}$ from the low temperature region. The Heisenberg model [31] states that for ferromagnetic materials, $T_{C}=\theta$, and that for antiferromagnetic materials, $T_{N}=-\theta$. The latter appears to be the case for most of the $\mathrm{A}_{\mathrm{x}} \mathrm{VF}_{3}$ compounds. However, magnetic frustrations present in the structures of $\alpha, \beta$, and $\delta$ should suppress $T_{N}$ values, making them much smaller than $|\theta|$ values $[32,33]$. This is the case with some of the $\beta$-phase compounds of $\mathrm{K}_{\mathrm{x}} \mathrm{VF}_{3}$ and all of the $\mathrm{A}_{\mathrm{x}} \mathrm{CrF}_{3}$ compounds, except those of the $\beta$-phase of $\mathrm{K}_{\mathrm{x}} \mathrm{CrF}_{3}$. For antiferromagnetic interactions $\theta$ values are negative; for ferromagnetic interactions $\theta$ is positive. Overall, the $\mathrm{Cr}$ compounds display antiferromagnetic behavior, but the $\mathrm{V}$ compounds may possess a mixture of ferromagnetic and antiferromagnetic coupling.

Spontaneous magnetic moments in zero field $\left(\sigma_{\mathrm{o}}\right)$, extrapolated to $0 \mathrm{~K}$ for the six $\mathrm{A}_{\mathrm{x}} \mathrm{MF}_{3}$ systems, are illustrated in Figure 9. The figure shows two kinds of spontaneous magnetic moments: ferromagnetic moments, shown as black areas, and ferrimagnetic moments, shown as hatched areas. The compounds which display no spontaneous moments are antiferromagnetic, and are shown as blank areas.

The $\mathrm{V}$ and $\mathrm{Cr}$ compounds show important differences in their magnetically ordered states. In these compounds, ferromagnetic order occurs from the canting of ordered spins; ferrimagnetic order means $\mathrm{M}^{2+}$

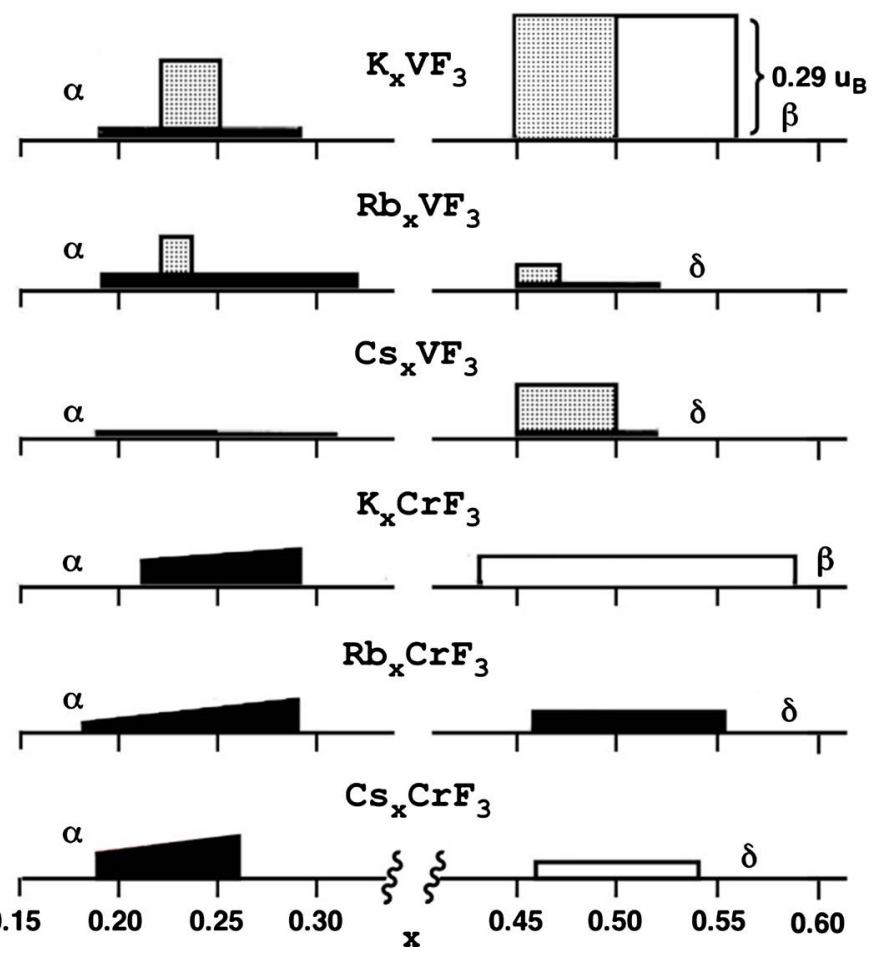

Figure 9. Spontaneous magnetic moments in zero field, extrapolated to $0 \mathrm{~K}$, of the $\mathrm{A}_{\mathrm{x}} \mathrm{MF}_{3}$ systems. Hatched areas correspond to ferrimagnetic compositions/phases, black areas to ferromagnetic compositions/phases caused by canting of spins, and blank areas represent compositions which have zero spontaneous magnetization. Data from refs [11-15]. 
spins are up while $\mathrm{M}^{3+}$ spins are down; and antiferromagnetic order means half of $\mathrm{M}^{2+}$ spins are up, half down, while half of $\mathrm{M}^{3+}$ spins are up, half down. Ferromagnetic ordering occurs in the $\alpha$ phases of all of the compounds and in the $\delta$-phases of $\mathrm{Rb}_{\mathrm{x}} \mathrm{VF}_{3}, \mathrm{Cs}_{\mathrm{x}} \mathrm{VF}_{3}$, and $\mathrm{Rb}_{\mathrm{x}} \mathrm{CrF}_{3}$. The $\mathrm{V}$ compounds demonstrate ferrimagnetic ordering in the $\alpha(0.222)$ structures of $\mathrm{K}_{\mathrm{x}} \mathrm{VF}_{3}$ and $\mathrm{Rb}_{\mathrm{x}} \mathrm{VF}_{3}$, in the $\beta$-phase of $\mathrm{K}_{\mathrm{x}} \mathrm{VF}_{3}$ below $\mathrm{x}=$ 0.49 , and in the fcc structure of the $\delta$-phases of $\mathrm{Rb}_{\mathrm{x}} \mathrm{VF}_{3}$ and $\mathrm{Cs}_{\mathrm{x}} \mathrm{VF}_{3}$, but no ferrimagnetic ordering was observed in any $\mathrm{Cr}$ compound. The $\beta$-phase of $\mathrm{K}_{\mathrm{x}} \mathrm{CrF}_{3}$ and the $\delta$-phase of $\mathrm{Cs}_{\mathrm{x}} \mathrm{CrF}_{3}$ are antiferromagnetic over their range of $\mathrm{x}$; the $\mathrm{K}_{\mathrm{x}} \mathrm{VF}_{3} \beta$-phase is antiferromagnetic above $\mathrm{x}=0.49$.

The ferrimagnetic mechanism of the $\beta$-phase of $\mathrm{K}_{\mathrm{x}} \mathrm{VF}_{3}$ was described in detail previously, [11] as was that of the $\alpha(0.222)$ structure in $\mathrm{K}_{\mathrm{x}} \mathrm{VF}_{3}$ and $\mathrm{Rb}_{\mathrm{x}} \mathrm{VF}_{3}$ [12]. In the $\delta$-phases of $\mathrm{Rb}_{\mathrm{x}} \mathrm{VF}_{3}$ and $\mathrm{Cs}_{\mathrm{x}} \mathrm{VF}_{3}$ ferrimagnetism occurs only in the fcc structure.

$\mathrm{MF}_{6}$ octahedra are canted in the HTB structure and the MP structure, but in the HTB and $\mathrm{BaTa}_{2} \mathrm{O}_{6}$ structures, there is no canting of the octahedra. The canting of spins (shown in Figure 9) is consistent with the canting of octahedra, except for the $\delta$-phase of $\mathrm{Cs}_{\mathrm{x}} \mathrm{CrF}_{3}$, which, strangely enough, has no spontaneous moment. In general, the canting of spins is greater in the $\mathrm{Cr}$ compounds. Most notably, canting within the $\operatorname{Cr} \alpha$-phases increases with $\mathrm{x}$.

\section{CONCLUDING REMARKS}

This paper identifies the solid-state transitions of the mixed valence $A_{x} M_{3}$ compounds from their respective melting temperatures down to $4.2 \mathrm{~K}$. This summary is organized to show connections of composition and structure with transitions and other events. The transitions occur in the following order:

melting $\rightarrow$ cubic perovskite $\rightarrow \alpha, \beta, \delta \rightarrow$ ionic order $\rightarrow$ orbital quenching of $\mathrm{V}^{3+} \rightarrow$

$\rightarrow$ magnetic order.

Other features and events include:

- the V compounds melting $200^{\circ}$ higher than their Cr analogs;

- the $\mathrm{V}$ compounds undergoing ionic ordering $200^{\circ}$ lower than their $\mathrm{Cr}$ analogs;

- single geometric structure;

- variations of orbital quenching of $\mathrm{V}^{3+}$;

- differences of $\beta$-phases of $\mathrm{V}$ and $\mathrm{Cr}$;

- differences of $-\theta / T_{N}$ of $\mathrm{V}$ and $\mathrm{Cr}$;

- metamagnetic transition of $\mathrm{K}_{0.49} \mathrm{VF}_{3}$;

- array of different magnetic interactions;

- canting of magnetic spins.

The study of the $\mathrm{A}_{\mathrm{x}} \mathrm{MF}_{3}$ compounds is a good introduction to an unchartered area of solid-state chemistry. Hopefully, similar studies of other systems will follow. The future breadth and depth of solid-state chemistry will be determined by the curiosity, creativity, and perseverance of solid-state chemists. High-quality powder diffraction data followed by a careful Rietveld analysis, or else crystal structure determinations (if and when crystals are obtained) should in the future buttress the arguments made here about the inferred onset of charge ordering as the symmetry is lowered. The lower-valence transition metal fluorides may ultimately yield exciting new phenomena complementary to the overwhelming success of the lower-valence transition metal oxides. Now that both Paul Hagenmuller and his competitor William Boo are gone, the next generation of chemists will hopefully pick up the challenge.

\section{ACKNOWLEDGEMENTS}

This work was supported by the National Science Foundation and the University of Mississippi. We thank Prof. Jared Allred for helpful discussions.

\section{CONFLICTS OF INTEREST}

The authors declare no conflicts of interest regarding the publication of this paper. 


\section{REFERENCES}

1. Goodenough, J.B. and Longo, J.M. (1970) Crystallographic and Magnetic Properties of Perovskites and Perovskite-Related Compounds. In: Hellwege, K.-H., Ed., Landolt-Börnstein Numerical Data and Functional Relationships in Science and Technology, New Series. Group III: Crystal and Solid State Physics: Vol. 4, Magnetic and Other Properties of Oxides and Related Compounds, Part A, Springer, Berlin, Heidelberg, New York.

2. Bednorz, J.G. and Müller, K.A. (1986) Possible High $T_{c}$ Superconductivity in the Ba-La-Cu-O System. Zeitschrift für Physik B Condensed Matter, 64, 189-193. https://doi.org/10.1007/BF01303701

3. Wu, M.K., Ashburn, J.R., Torng, C.J., Hor, P.H., Meng, R.L., Gao, L., Huang, Z.J., Wang, Y.G. and Chu, C.W. (1987) Superconductivity at $93 \mathrm{~K}$ in a New Mixed-Phase Y-Ba-Cu-O Compound System at Ambient Pressure. Physical Review Letters, 58, 908-910. https://doi.org/10.1103/PhysRevLett.58.908

4. Metzger, R.M. (1988) High-Temperature Superconductivity-The First Two Years. Gordon and Breach, New York.

5. Kang, M., Pelliciari, J., Frano, A., Breznay, N., Schierle, E., Weschke, E., Sutarto, R., He, F., Shafer, P., Arenholz, E., Chen, M., Zhang, K., Ruiz, A., Hao, Z., Lewin, S., Analytis, J., Krockenberger, Y., Yamamoto, H., Das, T. and Comin, R. (2019) Evolution of Charge Order Topology across a Magnetic Phase Transition in Cuprate Superconductors. Nature Physics, 15, 335-340. https://doi.org/10.1038/s41567-018-0401-8

6. Hagenmuller, P. (1985) Inorganic Solid Fluorides. Academic Press Inc., New York, 77-203.

7. Yeh, Y.K., Hong, Y.S., Boo, W.O.J. and Mattern, D.L. (2005) High-Temperature DTA Studies of $A_{x} M_{3}$ Compounds ( $\mathrm{A}=\mathrm{K}, \mathrm{Rb}, \mathrm{Cs} ; \mathrm{M}=\mathrm{V}$, Cr; and $\mathrm{x}=0-1.0)$. Journal of Solid State Chemistry, 178, 2191-2196.

https://doi.org/10.1016/j.jssc.2005.04.028

8. Dumora, D., Ravez, I. and Hagenmuller, P. (1972) Les séries $\mathrm{M}_{\mathrm{x}} \mathrm{CrF}_{3}$ (M = elément alcalin). Journal of Solid State Chemistry, 5, 35-39. https://doi.org/10.1016/0022-4596(72)90005-9

9. Cros, C., Feurer, R., Pouchard, M. and Hagenmuller, P. (1975) Les bronzes fluores de vanadium. Materials Research Bulletin, 10, 383-391. https://doi.org/10.1016/0025-5408(75)90009-4

10. Hong, Y.S., Williamson, R.F. and Boo, W.O.J. (1979) Lower Valence Fluorides of Vanadium. 3. Structures of the Pseudohexagonal $\mathrm{A}_{\mathrm{x}} \mathrm{VF}_{3}$ Phases (Where $\mathrm{A}=$ Potassium, Rubidium, Thallium, or Cesium). Inorganic Chemistry, 18, 2123-2125. https://doi.org/10.1021/ic50198a013

11. Hong, Y.S., Williamson, R.F. and Boo, W.O.J. (1980) Lower Valence Fluorides of Vanadium. 5. Dependence of Structure and Magnetic Properties of Tetragonal $\mathrm{K}_{\mathrm{x}} \mathrm{VF}_{3}$ on Composition. Inorganic Chemistry, 19, 2229-2233. https://doi.org/10.1021/ic50210a006

12. Hong, Y.S., Williamson, R.F. and Boo, W.O.J. (1981) Lower Valence Fluorides of Vanadium. 6. Dependence of Structure and Magnetic Properties of the Pseudohexagonal $\mathrm{A}_{\mathrm{x}} \mathrm{VF}_{3}$ Compounds on Composition. Inorganic Chemistry, 20, 403-409. https://doi.org/10.1021/ic50216a017

13. Hong, Y.S., Baker, K.N., Williamson, R.F. and Boo, W.O.J. (1984) Lower Valence Fluorides of Chromium. 1. The Hexagonal Bronze Type Phase Rubidium Chromium Fluoride $\left(\mathrm{Rb}_{\mathrm{x}} \mathrm{CrF}_{3}\right)$. Inorganic Chemistry, 23, 2787-2793. https://doi.org/10.1021/ic00186a015

14. Hong, Y.S., Baker, K.N., Shah, A.V., Williamson, R.F. and Boo, W.O.J. (1990) Lower Valence Fluorides of Chromium. 2. The Phase Potassium Chromium Fluoride $\left(\mathrm{K} 0.43-0.59 \mathrm{CrF}_{3}\right)$. Inorganic Chemistry, 29, 3037-3041. https://doi.org/10.1021/ic00341a036

15. Hong, Y.S. (1980) The Dependence of Structural and Magnetic Properties of A(x) Vanadium-Trifluoride Compounds on Composition. Ph.D. Dissertation, University of Mississippi, Oxford, MS.

16. Robin M.B. and Day, P. (1967) Mixed Valence Chemistry: A Survey and Classification. In: Emeleus, H.J. and Sharpe, A.G., Eds., Advances in Inorganic Chemistry and Radiochemistry, Vol. 10, Academic Press, New York, 
247-422. https://doi.org/10.1016/S0065-2792(08)60179-X

17. Hagenmuller, P. (1985) Inorganic Solid Fluorides. Academic Press Inc., New York, 94-96.

18. Xiao, Y., Su, Y., Li, H.-F., Kumar, C.M.N., Mittal, R., Persson, J., Senyshyn, A., Gross, K. and Brueckel, T. (2010) Neutron Diffraction Investigation of the Crystal and Magnetic Structures in $\mathrm{KCrF}_{3}$ Perovskite. Physical Review B, 82, Article ID: 094437. https://doi.org/10.1103/PhysRevB.82.094437

19. Leblanc, M., Maisonneuve, V. and Tressaud, A. (2015) Crystal Chemistry and Selected Physical Properties of Inorganic Fluorides and Oxide-Fluorides. Chemical Reviews, 115, 1191-1254. https://doi.org/10.1021/cr500173c

20. Wells, A.F. (1962) Structural Inorganic Chemistry. Oxford University Press, London, 495.

21. Magnéli, A. (1953) Studies on the Hexagonal Tungsten Bronzes of Potassium, Rubidium, and Cesium. Acta Chemica Scandinavica, 7, 315-324. https://doi.org/10.3891/acta.chem.scand.07-0315

22. Magnéli, A. (1949) The Crystal Structure of Tetragonal Potassium Tungsten Bronze. Arkiv för Kemi, 1, 213-221.

23. Layden, G.K. (1968) Dielectric and Structure Studies of Hexagonal $\mathrm{BaTa}_{2} \mathrm{O}_{6}$. Materials Research Bulletin, 31, 349-359. https://doi.org/10.1016/0025-5408(68)90006-8

24. Babel, D., Pausewang, G. and Viebahn, W.Z. (1967) Die Struktur einiger Fluoride, Oxide und Oxidfluoride $\mathrm{AMe}_{2} \mathrm{X}_{6}$ : Der RbNiCrF${ }_{6}$-Typ. Zeitschrift für Naturforschung B, 22, 1219-1220. https://doi.org/10.1515/znb-1967-1126

25. Sturm, B.J. (1962) Phase Equilibria in the System Chromium (II) Fluoride-Chromium (III) Fluoride. Inorganic Chemistry, 1, 665-672. https://doi.org/10.1021/ic50003a043

26. Boo, W.O.J. and Mattern, D.L. (2008) Concomitant Ordering and Symmetry Lowering. Journal of Chemical Education, 85, 710-717. https://doi.org/10.1021/ed085p710

27. Williamson, R.F. and Boo, W.O.J. (1977) Lower Valence Fluorides of Vanadium. 2. Characterization of the Tetragonal Phase $\mathrm{K}_{\mathrm{x}} \mathrm{VF}_{3}$. Inorganic Chemistry, 16, 649-651. https://doi.org/10.1021/ic50169a031

28. Dumora, D., Ravez, J. and Hagenmuller, P. (1970) $\mathrm{K}_{\mathrm{x}} \mathrm{CrF}_{3}$ Series. Bulletin de la Société Chimique de France, 1751-1752.

29. Gossard, A.C., Guggenheim, K.L., Hsu, F.S.L. and Sherwood, R.C. (1971) Magnetic Ordering of VF. AIP Conference Proceedings, 5, 302-306. https://doi.org/10.1063/1.3699445

30. Boo, W.O.J. and Stout, J.W. (1979) Heat Capacity and Entropy of $\mathrm{CuF}_{2}$ and $\mathrm{CrF}_{2}$ from 10 to $300{ }^{\circ} \mathrm{K}$. Anomalies Associated with Magnetic Ordering and Evaluation of Magnetic Contributions to the Heat Capacity. The Journal of Chemical Physics, 71, 9-16. https://doi.org/10.1063/1.438064

31. Kittel, C. (1967) Introduction to Solid State Physics. 3rd Edition, John Wiley \& Sons, Inc., New York, 456.

32. Hagenmuller, P. (1985) Inorganic Solid Fluorides. Academic Press Inc., New York, 395-413.

33. Hong, Y.S., Williamson, R.F. and Boo, W.O.J. (1980) Some Lower Valence Vanadium Fluorides: Their Crystal Distortions, Domain Structures, Modulated Structures, Ferrimagnetism, and Composition Dependence. Journal of Chemical Education, 57, 583-587. https://doi.org/10.1021/ed057p583 